\title{
Gota en un lactante
}

\author{
Dra. Alejandra Cerón C.1 $;$ Dra. Martha Ptuyas A. ${ }^{2}$ \\ Gout in an eight weeks old infant
}

\begin{abstract}
An intant was adtrited to hospital at the age of $11 / 2$ montls because of no weiglt gain, fever, food rejection, dehydration, muscle hypotonia, genexalized diminution of spinal reftexes and severe hyponitremia. He was manged with parenteral fluids and antibacterjal drugs. At the fourtl day from admission he had olema, low urine output persistent hyponatremia, metabolic acidosis and elevated blood urea. At the ninth hospital-day liver enlargenent was detected and several hard, elastic, smootli nodules not larger than $1 \mathrm{~cm}$ in diameter appeared on the back of the right liand and font lately jaundice was evident and the patient died two weeks after admission. Autopsy findings included uric acid deposits in both kjdneys, adrenal glands. lungs, páncreis, liver and the skin of hands and feet.

(Key words: (;out in infancy, hyperuricemia, delydration).
\end{abstract}

La gota constituye uni atección extremadamente poco frecuente en la infancia. Lais primeras descripciones se remontan a Morgagni, Gairdner (1854). Ganod (1876). Still (1927) y Mayer von Scloopf (1930). En 1959. Riley ${ }^{1}$ comunicó el caso de un niño de 8 años en el que coexistía una Gota típica desde los 3 años con una parálisis cerebral atctoide reconocida al ano de edad, sin relacionar ambas entidades. En 1964 , Lesh y Vyhan $^{2}$ describieron un sindrome caracterizado por hiperuricemia, retardo mental. coreoacetosis $y$ automutilación. En 196?. Michener ${ }^{3}$ comunicó 6 casos del sindrome, que consiste en un error congénito del metabolismo de las purinas: el gen mutante se encuentra en el cromosoma $X$, se expresan sólo en el sexo masculino, y corresponde a un déficit de la enzima hipoxantina-guanina-fosforibosil-transferasa $(\mathrm{HHRT})^{a, 5}$. En la Figura l se presenta un esquema simplificado del metabolismo de las purinas ${ }^{6}$

Las purinas adenina $y$ guanina, gue son necesar ias para la síntesis de los ácidos ribonucleico y desoxiribonucleico, se obtienen de la dieta o pueden ser sintetizadas de nuevo con los metabolitos disponibles. Estas bases pur ínicas normalmente son catabolizadas a través de la hipoxantina y la xancina, y excretadas como ácido úrico. Por un mecanismo de reutilización, se conserva parte de la hupoxantina, la cual, mediante una reacción dependiente de la HFRT, se convierte

1. Servicio de Pediatría, Hospital Sótero del Río. SSMSO.

2. Servicio de Anatom ía Patológica, Hospital Sótero del Río. SSMSO. en su nucleótido, el acido inosínico. Esta misma enzima convierte la base guanina en su nucleótiin. el ácido guanílico. Las concentraciones de estos dos nucleótidos, además del ácido adenilico. formado a expensas de la base adenina por und enzima diferente, controlan por retroalimen. tación el ritmo de la nueva sintesis de ácido inosínico. Si no se reutilizan la guanina y la hipoxantina, por falta de la enzima correspon. diente, no se logra la retroalimentación, y por consiguiente, aumenta la sintesis de purinas y se excreta un exceso de ácido úrico.

La hiperuricemia en el adulto incluye un grupo bastante heterogéneo de trastornos, algunos de los cuales recién están comenzando a ser definjdos. Clásicamente, se describe una forma transmitida por un gen autosómico dominante con grados diferentes de penetrancia en ambos sexos, siendo su expresión 6 a 7 vèces mayor en el hombre, en ella habría una biosíntesis exage. rada de nucleoproteínas. Otra torma, mucho menos frecuente, consiste en déficit de la HFRT que sólo alcanza niveles de 5 a $10 \%$ de lo normal.

\section{Caso Clínico}

Pacjente de sexo masculino, nació mediante cesárea por sufrimiento fetal agudo. Al nacer pesó $3.380 \mathrm{~g}$ y fue controlado en consultorio externo por desnutrición y síntomas sugerentes de reflujo gastro esofágico.

Ingresó a la edad de un mes y medio con antecedentes de fiebre, disminución de la actividad física, rechazo de los alimentos, tos y deposiciones semilíquidas. Pesaba $2.830 \mathrm{~g}$, estaba sin fiebre, tenia evidencia de deshidtatación moderada; hipotonia muscular e hiporreflexia, ambas 

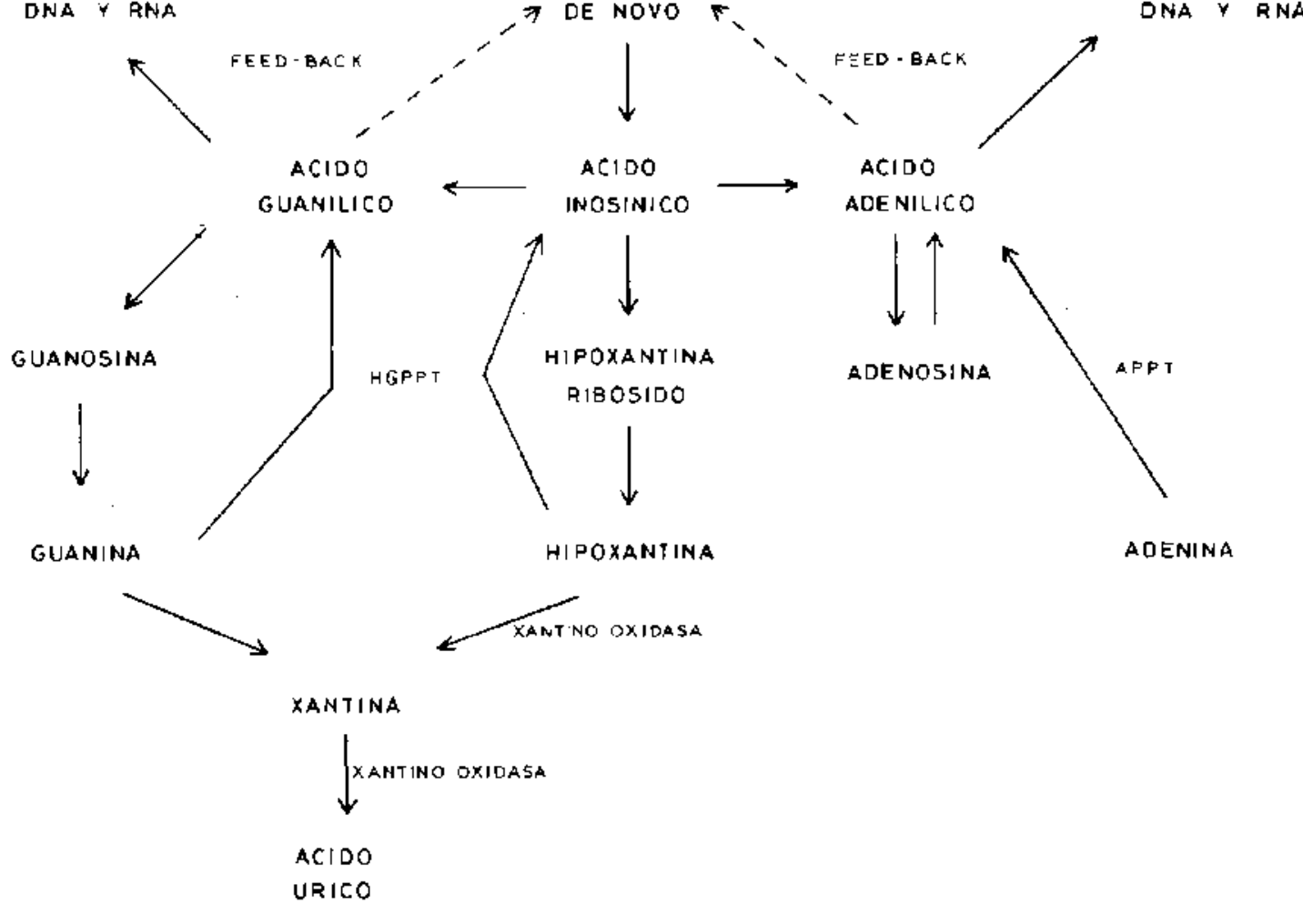

DNA Y RNA

Figura 1. Esquema simplificado del metabolismo de las purinas. Adaptado de Nelson, Vaugham amd Kc Kay. A textbook of Pediatrics, Fleventh Edition: 549, 1979.

generalizadas; hiponatremia severa ( $\mathrm{Na} 104 \mathrm{mEq}$ $x$ 1) y alteraciones del hemograma que fueron interpretadas como sugerentes de infección bacteriana (Leucocitos $20.300 \times \mathrm{mm}^{3}$ con $12 \%$ de baciliformes, $66 \%$ segmentados y granulaciones tóxicas de neutrófilos). En el segundo día de su hospitalización sufrió un episodio convulsivo generalizado, $\sin$ alteraciones concomitantes del liquido cefalorraquídeo, que cedió en coincidencja con el empleo de diazepam y fenobarbital. Desde el cuarto día se detectó edema, que aumentó progresivamente, disminución de la diuresis, hiponatremia persistente, acidosis metabólica, aumento anormal de la urea sanguínea $y$ desde el sexto dia hepatomegalia y esplenomegalia. En el noveno día apareció, en el dorso de su mano derecha, un nódulo liso, bien delimitado, de consistencia cartilaginosa, de $1 \mathrm{~cm}$ de diámetro, junto con otros similares pero de menor tamaño en el dorso del pie derecho, los que fueron puncionados sin resultado. EI día 14 se agregó ictericia y se observó aumento en el número y tamaño de los nódulos descritos, falleciendo quince días después de ingresar al hospital.

Su tratamiento consistió en el suministro de líquidos y bicarbonato de sodio por vía endove-

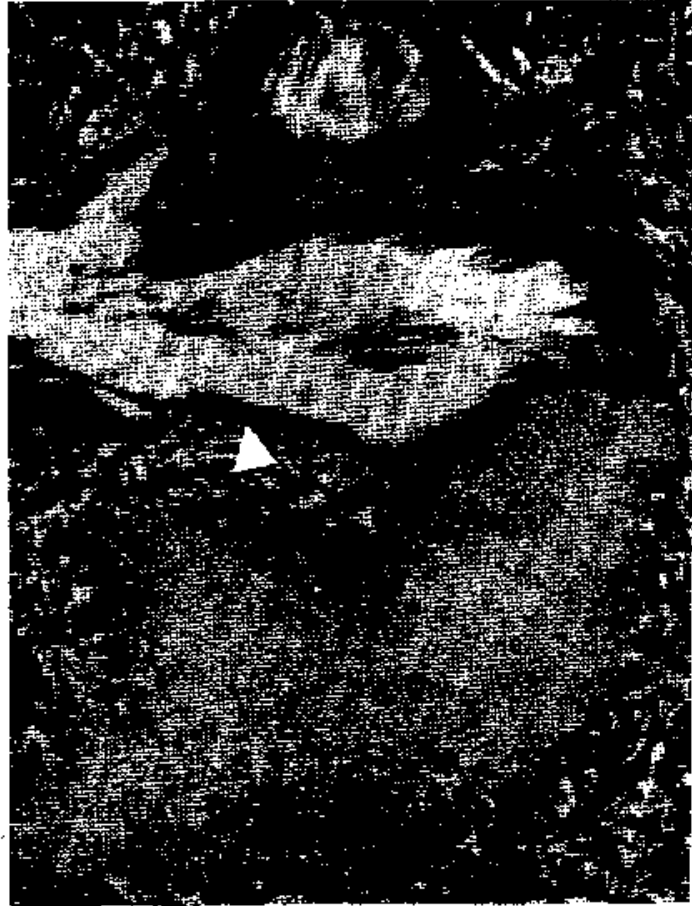

Figura 2. Acúmulo de cristales de ácido úrico en el parénquima renal. Tinción empleada en la fotografía: hematoxilina-eosina. Aumento: $40 \mathrm{x}$ 
nosa para cubrir los requetimientos y reparar sus trastornos hidroelectrolíticos: Penicilina y Gentamicina en la primera semana, las que fueron reemplazadas por Cloxacilina, Dibekacina $y$ Cefalotina durante la segunda y posteriormente por Amikacina, Carbenicilina, y Cefalotina el último día.

Su estudio anátomo-patológico demostró depósitos caracter ísticos de ácido úrico en los riñones (Fig. I), pulmones, glándulas suprarrenales, páncreas, hígado, manos y pies, que se acompañaban con evidencias de gastritis aguda necrótica y hemorrágica, enterocolitis aguda necrótica y hemorrágica y desnutrición.

\section{COMENTARIO}

Este caso resulta de singular interés por los sorprendentes resultados anátomo-patológicos.

Rosenthal y Cols. ${ }^{7}$ comunicaron en 1964 un caso de híperuricemia en un niño de término, de sexo masculino que pesó al nacer $4.205 \mathrm{~g}$. en cuyos pañales apareció un material color rojo ladrillo a las 3 semanas de edad, que aumentó progresivamente y que fue estudiado a la edad de tres meses por vómitos y deshidratación. Los exámenes del pañal revelaron que la sustancia era ácido úrico, del cual existín abundantes cristales en la orina, en coincidencia con uricemia de $18,6 \mathrm{mg} \%$. El paciente fue tratado con liquidos por vía parenteral en grandes volúmenes y citrato de sodio como alcalinizante de la orina. A los 3 años de edad seguia recibiendo citrato de sodio $y$ su desarrollo era completamente normal. Un estudio familiar reveló la existencia de hiperuricemia en parientes de las líneas paterna y materna, planteándose que pudiera tratarse de un paciente homocigoto del gen responsable.

Como puede apreciarse, existe bastante similitud entre ambos casos, considerando la edad de presentación y la historia de vómitos y mal progreso ponderal. Lamentablemente no fue posible ubicar a los familiares de nuestro paciente para efectuar estudio metabólico.

Por otra parte, en un estudio comparativo efectuado en recién nacidos normales y en pacientes con sindrome de dificultad respiratoria idiopática ${ }^{B}$, se encontraron en el segundo grupo, valores de uricemia y uricosuria superiores respecto a los niños normales. La interpretación de este hallazgo fue que la hipoxia llevaría a un exceso de producción de acido úrico por mayor degradación de nucleóticos. En estos casos se ha recomendado mantener una hidratación y flujo urinario adecuados, y alcanilizar la orina para evitar que se precipiten uratos en los riñones.

Resulta difícil precisar cuál habría sido el pronóstico de este nif̃o sì se hubiese realizado oportunamente el diagnóstico. Esperamos, sin embargo haber dejado planteada la inquietud para buscar esta enfermedad en otros pacientes con manifestaciones semejantes, especialmente si tienen antecedentes familiares marcados de este trastorno.

\section{RESUMEN}

Se presenta un caso anátomo-clínico de Gota en un paciente de 1 mes y medio de edad, cuyo diagrióstico, confirmado por la autopsia, no fue sospechado durante su evolución. Son muy pocos los casos publicados a tan corta edad y puede concluirse que se trata de un caso excepcional. Se mencionan otros trastornos relacionados de interés pediátrico.

\section{REFERENCIAS}

1. Riley, I.D.: Gout and cetebral palsy in a 3 years old boy. Ach Dis Child 35: 293, 1960.

2. Lesch, M., Nyhon, W.L.: A familial disorder or uric acid metabolism and central nervous system function. Am J Mod 36: 561, 1964.

3. Michener, W.M.: Hyperuricemia and mental retardation, with athetosis and self-mutilation. Am J Dis Child 113: 195, 1967

4. Nyhan, L.: Behavoir in the Lesh Nyhan Syndrome. J Aut Child Schizophrenia 6: 235, 1976.

5. Perfumo, F., Basile, G.C., Gusmamo, R.: Nefropatia aratica nelt infanzja. La malattia di Lesch Nyhan. Minerva Nefrol 23: 201, 1976.

6. Seegmiller, G.J.: Purine and Pyrirnidine metabolism, in: Bondy, P., Rosenbergk, L.: Metabolic control and disense, 8th edition, W.B. Saunders Co. Philadelphia, London, Totonto, 1980, Chap 12, pág. 793

7. Rosenthal. I., Gabalkh, S., Rafelson, M.: Gout in irfancy manifested by renal failure. Pediatrics 33: $251,1964$.

8. Raivio, K.O.: Neonatal hyperuricemia. J Pediatr 88: 625,1976 . 